University of Nebraska - Lincoln

DigitalCommons@University of Nebraska - Lincoln

1998

Dose-Response and Age- and Temperature-Related Susceptibility

of the Diamondback Moth (Lepidoptera: Plutellidae) to Two Isolates of Beauveria bassiana (Hyphomycetes: Moniliaceae)

John D. Vandenberg

USDA-ARS

Mark Ramos

USDA-ARS

Jennifer Altre

USDA-ARS

Follow this and additional works at: https://digitalcommons.unl.edu/entomologyother

Part of the Entomology Commons

Vandenberg, John D.; Ramos, Mark; and Altre, Jennifer, "Dose-Response and Age- and TemperatureRelated Susceptibility of the Diamondback Moth (Lepidoptera: Plutellidae) to Two Isolates of Beauveria bassiana (Hyphomycetes: Moniliaceae)" (1998). Entomology Papers from Other Sources. 53.

https://digitalcommons.unl.edu/entomologyother/53

This Article is brought to you for free and open access by the Entomology Collections, Miscellaneous at DigitalCommons@University of Nebraska - Lincoln. It has been accepted for inclusion in Entomology Papers from Other Sources by an authorized administrator of DigitalCommons@University of Nebraska - Lincoln. 
BIOLOGICAL CONTROL

\title{
Dose-Response and Age- and Temperature-Related Susceptibility of the Diamondback Moth (Lepidoptera: Plutellidae) to Two Isolates of Beauveria bassiana (Hyphomycetes: Moniliaceae)
}

\author{
JOHN D. VANDENBERG, MARK RAMOS, AND JENNIFER A. ALTRE ${ }^{1}$
}

Plant Protection Research Unit, U.S. Plant, Soil and Nutrition Laboratory, USDA-ARS, Tower Road, Ithaca, NY 14850

Environ. Entomol. 27(4): 1017-1021 (1998)

ABSTRACT Two isolates of Beauceria bassiana (Balsamo) Vuillemin were used in bioassays against the diamondback moth, Plutella xylostella (L.). One isolate, ARSEF 4543, originated from a diamondback moth larva collected in New York and the other, Mycotech GHA, is the active ingredient in Mycotrol, a product registered for control of insect species belonging to several orders. Doseresponse assays of suspended spores sprayed on larvae resulted in similar $L_{5} D_{50}$ ( 518 and 614 spores per square centimeter for ARSEF 4543 and Mycotech GHA, respectively) but different slopes for the probit regression lines $(0.64$ and 0.89$)$. Survival times for larvae inoculated at a range of dosages were variable for ARSEF 4543 but decreased with increasing dosages for Mycotech GHA. Third and 4 th instars were more susceptible than 2nd instars, although survival times varied between the 2 isolates for different instars. Larvae inoculated early in the 2nd or 3rd instar had shorter suvival times than those inoculated later in each instar. Spores of B. bassiana were readily detected on exuviae from inoculated larvae using fluorescence microscopy, indicating the significance of molting as a means of avoiding infection. The isolates did not differ significantly in their activities over a range of temperatures. Highest mortality and lowest survival times were observed at $25^{\circ} \mathrm{C}$; mortality decreased and survival time increased at temperatures both above and below $25^{\circ} \mathrm{C}$. These findings provide baseline information on the susceptiblity of P. xylostella to B. bassiana and they indicate the potential utility of a commercial preparation of B. bassiana for use against $P$. xylostella in the field.

KEY WORDS Plutella xylostella, Beauveria bassiana, microbial control, bioassay, entomopathogenic fungus, virulence

THE DIAMONDBACK MOTH, Plutella xylostella (L.), is the most important pest worldwide of cultivated brassicas (Talekar and Shelton 1993). Chemical insecticides are used extensively against this pest, but it has developed resistance to many, including some formulations of Bacillus thuringiensis Berliner (Shelton et al. 1993).

Several fungi have been isolated from $P$. xylostella (Humber 1992), but few have been studied in detail. Recent descriptions of natural epizootics of 2 Entomophthorales species in Asian populations of $P$. $x y$ lostella (Riethmacher and Kranz 1994) have led to more detailed work on Zoophthora radicans (Brefeld) Batko infection of P. xylostella by others (Pell et al. 1993a, b). In Malaysia, Ibrahim and Low (1993) have shown the potential effectiveness of Beauveria bassiana (Balsamo) Vuillemin and Paecilomyces fumosoroseus (Wize) Brown \& Smith against P. xylostella in the field. More recently, Shelton et al. (1998) and Vandenberg et al. (1998) have shown that commercial formulations of B. bassiana can control P. xylostella

This article reports the results of research only. Mention of a proprietary product does not constitute an endorsement or a recommendation by USDA for its use.

${ }^{1}$ Department of Entomology, Cornell University, Ithaca, NY 14853. populations on crucifer seedlings in screenhouses and on larger plants in the field.

As a component of a research program to explore the use of $B$. bassiana for control or management of pest insects, we have developed a laboratory assay protocol to test the efficacy of $B$. bassiana and other fungi against $P$. xylostella. Elsewhere we report screening results against $P$. xylostella for 55 isolates of $B$ bassiana, Fusarium sp., Metarhizium anisopliae (Metschnikoff) Sorokin, and Paecilomyces farinosus (Holm ex Gray) Brown \& Smith (Vandenberg and Ramos 1997). The objectives of this study were to determine the dose response and age- and temperature-related susceptibility of $P$. xylostella larvae to $2 B$. bassiana isolates. One of these was isolated from $P$. xylostella and the other was isolated from a commercial B. bassiana product.

\section{Materials and Methods}

The B. bassiana isolate ARSEF 4543 was obtained from the USDA-ARS Collection of Entomopathogenic Fungal Cultures (Ithaca, NY). This is a singlespore isolate derived from a single infected $P$. xylostella larva collected in Ontario County, NY. A 2nd isolate, Mycotech GHA, was obtained from the tech-

This article is a U.S. government work, and is not subject to copyright in the United States. 
nical powder of Mycotrol (Mycotech, Butte, MT), a $B$. bassiana product registered for control of certain species of Orthoptera, Homoptera, Heteroptera, Thysanoptera, and Coleoptera. Each isolate was initially passed through $P$. xylostella larvae and each was subcultured $<5$ times before use in assays. Cultures were maintained on Sabouraud dextrose agar plus $2 \%$ yeast extract (SDAY) at $24^{\circ} \mathrm{C}$ and a photoperiod of $15: 9$ (L:D) h. Fungal conidia were scraped from the surface of cultures 14-21 d old and suspended in $0.01 \%$ Tween 80 by vortexing for $2 \mathrm{~min}$. Suspensions were filtered through 16 layers of sterile cheesecloth to remove clumps and hyphal fragments. Spore concentrations were estimated using a hemacytometer and adjusted as needed, using additional $0.01 \%$ Tween 80 , for experiments described below. P. xylostella larvae treated only with the suspending medium $(0.01 \%$ Tween 80$)$ were included in each assay as controls. (Mortality among control larvae was minimal and no evidence of B. bassiana infection was detected.)

First instars of P. xylostella were obtained from A. M. Shelton (Geneva, NY) and incubated on wheat germ diet (Shelton et al. 1991) at $10^{\circ} \mathrm{C}$ and a photoperiod of 15:9 (L:D) h for 1-2 d. Larvae were used as 2 nd instars except as described below. For assays, larvae were transferred to petri dishes, 7-10 per dish, lined with moistened filter paper. Four dishes were assigned randomly to each treatment for each experiment. Insects were inoculated at room temperature $\left(\approx 22^{\circ} \mathrm{C}\right)$ using a Burgerjon spray tower (Burgerjon 1956) equipped with a Spraying Systems 2850 nozzle (Wheaton, IL). The nozzle was calibrated according to Vandenberg (1996) by spraying spore suspensions at a range of concentrations onto water agar and estimating their concentration by counting the spores. A suspension volume of $5 \mathrm{ml}$ was applied to each group of 4 dishes of larvae at an air flow rate of 5 liters $/ \mathrm{min}$ and at a dosage described below. After inoculation, two 1-cm disks of P. xylostella diet (Bioserv Premix) were added to each dish. The dishes were sealed with parafilm and incubated in darkness at $25^{\circ} \mathrm{C}$ (except as described below). After $24 \mathrm{~h}$, any dead insects were discarded and not counted. Living larvae were transferred to a sterile petri dish with fresh diet and incubated at $25^{\circ} \mathrm{C}$ (except as described below) and a photoperiod of 15:9 (L:D) h. Larvae were monitored daily and diet was replaced as needed for $7 \mathrm{~d}$. Dead larvae were removed to petri dishes containing a piece of moistened filter paper. Death from fungal infection was confirmed by observing characteristic fungal eruption from cadavers and subsequent sporulation. To confirm viability of spore suspensions, $5 \mathrm{ml}$ of each was sprayed on SDAY plates. Plates were incubated at $25^{\circ} \mathrm{C}$ and a photoperiod of 15:9 (L:D) h for 2-3 d until identifiable fungal colonies appeared. Colony counts confirmed deposition at the rates indicated (data not shown).

Dose-Response Assays. Larvae were inoculated with each isolate at dosages of $312,625,1,250,2,500$ and 5,000 spores per square centimeter. Assays were repeated 4 times for ARSEF 4543 and 3 times for Mycotech GHA. Probit analysis (SYSTAT 1997) was used to estimate $\mathrm{LD}_{50} \mathrm{~s}$, fiducial limits, and other regression parameters. Analysis of variance (ANOVA) was used to test the effect of dosage on survival time in days. Means were compared using the Tukey test (SYSTAT 1996).

Age-Related Susceptibility. First instars were incubated at $25^{\circ} \mathrm{C}$ and a photoperiod of 15:9 (L:D) h until they reached the $2 \mathrm{nd}$, 3rd, or 4 th instar. Newly molted larvae of each instar with visibly darkened cuticles were chosen for the tests. Seven to eleven larvae of each instar were placed in each of 4 dishes. Larvae were inoculated with either ARSEF 4543 or Mycotech GHA at a dosage of 625 spores per square centimeter and observed daily for $7 \mathrm{~d}$. The entire experiment was repeated twice. Analysis of variance was used to test for the effects of isolate and instar on angular-transformed percentage mortality and on survival time in days. Means were compared using the Tukey test (SYSTAT 1996).

To determine the effect of age within and instar, groups of 200 second and 3rd instars were subdivided into groups of 100 . Half were inoculated on the day of selection and the other half were inoculated the following day ( $20-24 \mathrm{~h}$ later). For inoculation, $2 \mathrm{ml}$ of a suspension of Mycotech GHA at $2 \times 10^{7}$ spores per milliliter was added to $100 \mathrm{~mm}$ sterile petri dishes lined with filter paper. Larvae were placed in the dishes without food for $1 \mathrm{~h}$ and then transferred individually to unlined petri dishes and provided with a small cube of $P$. xylostella diet. Dishes were sealed with parafilm. Larvae were checked twice daily for molting and mortality. Cast exuvia were recorded and removed when found, and the instar at death was recorded. Dead larvae were incubated for diagnosis as described above. Time to molt, survival time, and instar at death were compared for early- versus late-instar larvae using Student $t$-tests or the Pearson $\chi^{2}$ frequency distribution test (SYSTAT 1996).

For microscopy, additional larvae were inoculated as described above. Upon molting, cast skins were mounted in a drop of $0.01 \%$ Calcofluor white M2R (Sigma, St. Louis, MO) on a microscope slide with glass coverslip. Cuticle from the same recently molted larvae was removed by dissection and mounted in Calcofluor. Observations were made using an Olympus $\mathrm{BH} 2$ microscope with a mercury-lamp epiflourescence illuminator with an excitation wavelength of $390-440 \mathrm{~nm}$ (violet), chromatic beam splitter at 460 $\mathrm{nm}$, and barrier filter at $475 \mathrm{~nm}$.

Temperature-Related Susceptibility. Second instars were inoculated at a dosage of 625 spores per square centimeter. After inoculation, larvae were incubated in darkness at $15,20,25,30$, or $35^{\circ} \mathrm{C}$ for $24 \mathrm{~h}$ and then transferred to new dishes, as described above, and maintained at the same assigned temperature. The experiment was repeated 5 times using both fungal isolates. Mortality was assessed after $10 \mathrm{~d}$ for the 1 st experiment and daily for $10 \mathrm{~d}$ for the other 4 experiments. Five larvae were used per dish and there were 4 dishes per treatment. Analysis of variance was done to determine the effects of isolate and temperature on angular-transformed percentage mortality and on survival time in days. Means were compared using the 
Table 1. Probit analyses of 2 isolates of $B$. bassiana against 2 nd instars of the diamondback moth

\begin{tabular}{ccccc}
\hline Isolate & $\begin{array}{c}\text { No. } \\
\text { larvae }\end{array}$ & Slope $\pm \mathrm{SE}$ & $\begin{array}{c}\mathrm{LD}_{50}(95 \% \mathrm{FL}) \\
\left(\text { spores } / \mathrm{cm}^{2}\right)^{a}\end{array}$ & $\chi^{2}$ \\
\hline ARSEF 4543 & 691 & $0.64 \pm 0.12$ & $518(271-763)$ & 3.9 \\
Mycotech GHA & 423 & $0.89 \pm 0.13$ & $614(222-1,930)$ & 4.3 \\
\hline
\end{tabular}

Four assays for ARSEF 4543, 3 for Mycotech GHA, 7-10 insects per replicate, 4 replicates per dose, 5 doses per assay.

${ }^{a}$ Analyses done on $\log _{10}$ spores per square centimeter.

Tukey test (SYSTAT 1996). Nonlinear regression analysis was used to analyze the effect of temperature on survival time in days (SYSTAT 1996).

\section{Results}

Dose-Response Assays. Probit analysis was significant for ARSEF 4543 and for Mycotech GHA (Table 1). $L_{50}$ s were similar for the 2 isolates, and fiducial limits overlapped considerably, indicating no significant difference. A significant difference between the slopes was indicated by the interaction between isolate and dosage $\left(\chi^{2}=0.002, \mathrm{df}=1, P<0.04\right)$. Average survival time varied significantly with dosage for ARSEF $4543(F=7.0 ; \mathrm{df}=4,483 ; P<0.0001)$ and for Mycotech GHA $(F=20.3$; $\mathrm{df}=4,408 ; P<0.0001)$ (Table 2). For Mycotech GHA there was a decrease in survival time with increasing dosage. Survival times for ARSEF 4543 were lower at the 2 highest dosages and at an intermediate dosage.

Age-Related Susceptibility. The 2 fungal isolates differed significantly in their effect on angular-transformed percentage mortality $(F=12.6 ; \mathrm{df}=2,42 ; P<$ $0.0001)$ and on average survival time $(F=23.6$; df $=$ 1,$373 ; P<0.0001$ ) among larvae of different instars, so the effect of age on susceptibility was examined separately for each isolate. Mortality varied significantly among instars for each isolate (for ARSEF 4543: $F=$ $4.3 ; \mathrm{df}=2,21 ; P<0.03$; for Mycotech GHA: $F=7.6$; $\mathrm{df}=2,21 ; P<0.003$ ) (Table 3). Survival times also varied significantly among instars for each isolate (for ARSEF 4543: $F=5.4 ; \mathrm{df}=2,172 ; P<0.005$; for Mycotech GHA: $F=11.3 ; \mathrm{df}=2,201 ; P<0.0001)$. For

Table 2. Survival times (mean \pm SEM) for 2nd-instars of the diamondback moth inoculated with $B$. bassiana

\begin{tabular}{lccc}
\hline Isolate & $\begin{array}{c}\text { Dosage } \\
\left.\text { (spores } / \mathrm{cm}^{2}\right)\end{array}$ & $\begin{array}{c}\text { No. } \\
\text { mycoses }^{a}\end{array}$ & $\begin{array}{c}\text { Survival } \\
\text { time, d }\end{array}$ \\
\hline ARSEF & 312 & 71 & $5.3 \pm 0.2 \mathrm{a}$ \\
& 625 & 83 & $4.6 \pm 0.1 \mathrm{~b}$ \\
& 1,250 & 103 & $5.2 \pm 0.1 \mathrm{a}$ \\
Mycotech GHA & 2,500 & 118 & $4.8 \pm 0.1 \mathrm{ab}$ \\
& 5,000 & 113 & $4.5 \pm 0.1 \mathrm{~b}$ \\
& 312 & 78 & $4.6 \pm 0.1 \mathrm{a}$ \\
& 625 & 86 & $4.2 \pm 0.1 \mathrm{~b}$ \\
& 1,250 & 85 & $4.0 \pm 0.1 \mathrm{bc}$ \\
& 2,500 & 85 & $3.8 \pm 0.1 \mathrm{~cd}$ \\
& 5,000 & 79 & $3.5 \pm 0.1 \mathrm{~d}$ \\
\hline
\end{tabular}

Means for each isolate followed by the same letter are not significantly different (Tukey test, $P<0.05$ ).

${ }^{a}$ Combined results of $3-4$ experiments (see text).
Table 3. Percentage mortality (mean \pm SEM) and survival times for larvae of the diamondback moth inoculated at different ages with $B$. bassiana

\begin{tabular}{cccccc}
\hline Isolate & Instar & $\begin{array}{c}\text { No. } \\
\text { larvae }\end{array}$ & $\begin{array}{c}\% \\
\text { mortality }\end{array}$ & $\begin{array}{c}\text { No. } \\
\text { mycoses }\end{array}$ & $\begin{array}{c}\text { Survival } \\
\text { time, d }\end{array}$ \\
\hline ARSEF 4543 & 2 & 53 & $53 \pm 11 \mathrm{~b}$ & 28 & $4.4 \pm 0.4 \mathrm{a}$ \\
& 3 & 86 & $86 \pm 3 \mathrm{a}$ & 74 & $5.0 \pm 0.2 \mathrm{~b}$ \\
& 4 & 84 & $72 \pm 7 \mathrm{~b}$ & 60 & $4.6 \pm 0.3 \mathrm{a}$ \\
Mycotech GHA & 2 & 65 & $74 \pm 6 \mathrm{~b}$ & 48 & $4.5 \pm 0.2 \mathrm{a}$ \\
& 3 & 87 & $83 \pm 8 \mathrm{~b}$ & 72 & $4.0 \pm 0.2 \mathrm{~b}$ \\
& 4 & 83 & $100 \pm 0 \mathrm{a}$ & 83 & $4.2 \pm 0.1 \mathrm{~b}$ \\
\hline
\end{tabular}

Means for each isolate followed by the same letter are not significantly different (Tukey test, $P<0.05$ ).

${ }^{a}$ Combined results of 2 experiments (see text).

ARSEF 4543, significantly higher mortality and survival times were observed for 3rd instars. In contrast, for Mycotech GHA, highest mortality was observed among 4th instars, and lowest survival times were observed for 3rd and 4th instars.

Larvae inoculated earlier within the 2 nd or 3 rd instar had significantly lower survival times than those inoculated later in the instar (Table 4; for 2nd instars: $t=-1.93, \mathrm{df}=135, P<0.05$; for 3rd instars: $t=-4.77$, $\mathrm{df}=66, P<0.001)$. The age distribution by stage at death did not vary significantly between larvae inoculated early versus late within the 2 nd instar (Pearson $\chi^{2}=5.2, \mathrm{df}=3, P<0.16$ ), but it did vary significantly for larvae inoculated early versus late in the 3 rd instar (Pearson $\chi^{2}=29.5$; $\mathrm{df}=2 ; P<0.001$ ). Larvae inoculated early in the 3rd instar were most likely to die as larvae whereas larvae inoculated late in the 3rd instar were most likely to die as pupae.

Microscopic observations confirmed that spores of $B$. bassiana were abundant on exuvia from larvae inoculated late within the 2 nd or 3 rd instar (i.e., those larvae that molted soon after inoculation). Spores were rarely detected on cuticles dissected from larvae inoculated early in either instar.

Temperature-Related Susceptibility. Larval mortality and survival time varied significantly with temperature (for mortality: $F=7.8$; $\mathrm{df}=4,42 ; P<0.0001$; for survival time: $F=7.2 ; \mathrm{df}=4,464 ; P<0.0001)$ but not with isolate $(F=1.0 ; \mathrm{df}=1,42 ; P<0.18)$, so isolates were combined for further analysis. Highest mortality was observed among the intermediate temperatures of 20,25 , and $30^{\circ} \mathrm{C}$ (Table 5). Lowest survival times were observed at 25 and $30^{\circ} \mathrm{C}$. Mortality data were fit to a nonlinear, quadratic model: percentage mortality =

Table 4. Survival times (mean \pm SEM) for diamondback moth inoculated as 2nd or 3rd instars with B. bassiana isolate Mycotech GHA

\begin{tabular}{lccr}
\hline $\begin{array}{c}\text { Stage at } \\
\text { inoculation }\end{array}$ & $\begin{array}{c}\text { No. } \\
\text { inoculated }\end{array}$ & $\begin{array}{c}\text { No. } \\
\text { mycoses }\end{array}$ & $\begin{array}{r}\text { Survival } \\
\text { time, h }\end{array}$ \\
\hline Early 2nd instar & 100 & 82 & $73 \pm 3 \mathrm{a}$ \\
Late 2nd instar & 98 & 55 & $82 \pm 4 \mathrm{~b}$ \\
Early 3rd instar & 100 & 58 & $61 \pm 4 \mathrm{a}$ \\
Late 3rd instar & 98 & 10 & $106 \pm 6 \mathrm{~b}$ \\
\hline
\end{tabular}

Means within each instar followed by the same letter are not significantly different (Student $t$-test, $P<0.05$ ). 
Table 5. Percentage mortality (mean \pm SEM) and survival times of 2 nd instars of the diamondback moth inoculated with $B$. bassiana and incubated at different temperatures

\begin{tabular}{ccccc}
\hline \hline $\begin{array}{c}\text { Temp, } \\
{ }^{\circ} \mathrm{C}\end{array}$ & $\begin{array}{c}\text { No. } \\
\text { larvae }\end{array}$ & $\begin{array}{c}\% \\
\text { mortality }\end{array}$ & $\begin{array}{c}\text { No. } \\
\text { mycoses }\end{array}$ & $\begin{array}{c}\text { Survival } \\
\text { time, } \mathrm{b}^{a}\end{array}$ \\
\hline 15 & 210 & $18 \pm 6 \mathrm{~b}$ & 28 & $5.8 \pm 0.2 \mathrm{a}$ \\
20 & 206 & $52 \pm 10 \mathrm{a}$ & 105 & $5.9 \pm 0.2 \mathrm{a}$ \\
25 & 205 & $72 \pm 9 \mathrm{a}$ & 132 & $4.9 \pm 0.1 \mathrm{~b}$ \\
30 & 206 & $56 \pm 11 \mathrm{a}$ & 70 & $5.3 \pm 0.1 \mathrm{ab}$ \\
35 & 208 & $19 \pm 6 \mathrm{~b}$ & 34 & $5.8 \pm 0.4 \mathrm{a}$ \\
\hline
\end{tabular}

Means followed by the same letter are not significantly different (Tukey test, $P<0.05$ )

${ }^{a}$ Combined results for 2 isolates of B. bassiana.

$-2.52+0.26$ (temperature) -0.005 (temperature $\left.{ }^{2}\right)$. The $r^{2}$ was 0.40 , the residual mean square was 0.07 , and the standard errors were $0.54,0.04$, and 0.001 for intercept, temperature, and temperature ${ }^{2}$, respectively.

\section{Discussion}

The $\mathrm{LD}_{50}$ s we estimated (5.2 and $6.1 \times 10^{2}$ spores/ per square centimeter; Table 1) are lower than some, and higher than other, estimates of $B$. bassiana assayed against lepidopteran larvae. Higher $\mathrm{LD}_{50}$ s were estimated by Feng et al. (1985) in spray tower assays against Ostrinia nubilalis (Hübner). Among their $\mathrm{LD}_{50}$ estimates, the lowest was $8.4 \times 10^{3}$ colony-forming units $(\mathrm{CFU}) / \mathrm{cm}^{2}$ for $B$. bassiana isolate ARSEF 533 against the most susceptible instar (1st). Other $\mathrm{LD}_{50} \mathrm{~s}$ in their study ranged from $1.3 \times 10^{4}$ to $5.6 \times 10^{7}$ CFU per square centimeter. Ignoffo et al. (1982) estimated an $\mathrm{LD}_{50}$ of $1.4 \times 10^{4}$ spores per square centimeter for 1st instars of Trichoplusia ni (Hübner) using a leaf-disk treatment. McDowell et al. (1990) also used a leaf-surface treatment in assays against Elasmopalpus lignosellus (Zeller). Lower $\mathrm{LD}_{50}$ s were estimated for 1st instars (12 spores per square centimeter) than for 3rd instars (51 spores per square centimeter).

The slopes of the probit regression lines we estimated (Table 1) are within the range of those commonly estimated in assays of entomopathogens generally (Burges and Thomson 1971), and B. bassiana against lepidopteran larvae in particular. Slope estimates for assays of $B$. bassiana were 0.49-1.64 for $O$. nubilalis (Feng et al. 1985), 1.34 T. ni (Ignoffo et al. 1982), and 0.50-1.12 for E. lignosellus (McDowell et al. 1990).

We observed decreased survival times with increasing dosage for Mycotech GHA, but the trend was less distinct for ARSEF 4543 (Table 2). This may be caused by variability within the isolate, although it originated from a single spore. Perhaps the temperature optimum for ARSEF 4543, used in our study, is lower than the $25^{\circ} \mathrm{C}$ used in our tests. Carruthers et al. (1985) also observed decreasing survival times with increasing dosage for young larvae of $O$. nubilalis, but the relationship was less significant at higher temperatures and among older larvae. Survival times among 2nd instars reared at $26^{\circ} \mathrm{C}$, approximately the same tem- perature we used, ranged from $1.7 \mathrm{~d}$ at their highest dosage $\left(2.9 \times 10^{6} \mathrm{CFU} / \mathrm{cm}^{2}\right)$ to $3.9 \mathrm{~d}$ at their lowest $\left(2.3 \times 10^{4} \mathrm{CFU} / \mathrm{cm}^{2}\right)$. McDowell et al. (1990) observed decreasing $\mathrm{LT}_{50} \mathrm{~s}$ with increasing dosage for both instars tested of E. lignosellus (1st and $3 \mathrm{rd}$ ); times to death were $12-14 \mathrm{~d}$ for larvae inoculated at the $\mathrm{LD}_{\overline{5} 0}$.

We assayed B. bassiana against $2 \mathrm{nd}$, 3rd, and 4 th instars of $P$. xylostella because these are the feeding stages exposed on host plant leaf surfaces. Second instars were the least susceptible to infection (Table $3)$. This is caused by the shorter duration of early stages, the consequently increased likelihood of molting soon after inoculation, and subsequent shedding of spores with cuticle among early-stage larvae. Our observations of fungal spores on exuvia from recently inoculated larvae corroborates a similar finding of Vey and Fargues (1977) for larvae of the Colorado potato beetle, Leptinotarsa decemlineata (Say). The absence of spores on exuvia of larvae inoculated early in the 2nd or 3rd instar indicates that the spores had either been rubbed off through insect movements or had already germinated and penetrated the host cuticle.

In our tests, 4 th instars were most susceptible to infection by Mycotech GHA and intermediate in susceptibility to ARSEF 4543. Later instars have longer durations that allow the pathogen more time to establish infection before a molt would remove inoculum (Feng et al. 1985). Although we observed statistically significant differences among survival times for larvae inoculated with either isolate (Table 3), the estimates are all within a range of $1.0 \mathrm{~d}$.

We observed a clear optimum $\left(25^{\circ} \mathrm{C}\right)$ among temperatures for both mortality and survival time, but fungus infection occurred at all temperatures (Table $5)$. In contrast, Carruthers et al. (1985) obtained no infection of $O$. nubilalis larvae at $36^{\circ} \mathrm{C}$ and variable results at $31^{\circ} \mathrm{C}$. They also observed lower survival times at lower temperatures.

Plutella xylostella larvae vary in their susceptibility to infection by $B$. bassiana based on dosage, age, and temperature. We have shown that ARSEF 4543, originally isolated from a $P$. xylostella larva, is not significantly more efficacious than the commercial isolate Mycotech GHA. We also have shown that P. xylostella is susceptible to $B$. bassiana during all of the exposed feeding stages (2nd-4th instar) and over a range of temperatures common in the field.

Vandenberg and Ramos (1997) found no significant differences in infectivity among several $B$. bassiana isolates originating from $P$. xylostella and few differences among $46 \mathrm{~B}$. bassiana isolates. This is not surprising given the extremely broad host range of this fungus (Goettel et al. 1990, Feng et al. 1994). Mycotrol (with Mycotech GHA as the active ingredient) is labelled for use against insects in several orders, but not including Lepidoptera. However, Shelton et al. (1998) found that Mycotrol provided control of $P$. xylostella larvae resistant to $B$. thuringiensis on crucifer seedlings and suggested that $B$. bassiana may be useful as a control agent against insecticide-resistant populations. Vandenberg et al. (1998) found that Mycotrol 
applications on cabbage plants at the 10-12 leaf stage provided effective control of $P$. xylostella. However, action thresholds for P. xylostella are much lower on mature plants (Anonymous 1998), when damage to developing vegetative and flowering heads has greater impact. Current studies are aimed at evaluating the integration of $B$. bassiana with insecticides and other tools for season-long management of pests of crucifers.

\section{Acknowledgments}

We are grateful to Jomelle Bowen of our laboratory for technical assistance; to Tony Shelton, Juliet Tang, and Jennifer Cooley of Cornell University for rearing and providing insects; to Cliff Bradley and Stefan Jaronski of Mycotech Corporation for providing technical powder of the GHA isolate; to Tad Poprawski of Texas A \& M University for construction of the Burgerjon spray tower; and to Paresh Shah of the Swiss Federal Institute of Technology and Tony Shelton of Cornell University for useful critical reviews of the manuscript.

\section{References Cited}

Anonymous. 1998. Pest management recommendations for commercial vegetable and potato production. Cornell Cooperative Extension, Ithaca, NY.

Burgerjon, A. 1956. Pulverisation et poudrage au laboratoire par des preparations pathogenes insecticides. Ann. Epiphyt. 4: 675-684.

Burges, H. D., and E. M Thomson. 1971. Standardization and assay of microbial insecticides, pp. 591-622. $\ln \mathrm{H}$. D. Burges and N. W. Hussey [eds.], Microbial control of insects and mites. Academic, New York.

Carruthers, R. I., Z. Feng, D. S. Robson, and D. W. Roberts. 1985. In vivo temperature-dependent development of Beauceria bassiana (Deuteromycotina: Hyphomycetes) mycosis of the European corn borer, Ostrinia nubilalis (Lepidoptera: Pyralidae). J. Invertebr. Pathol. 46: 305311.

Feng, Z., R. I. Carruthers, D. W. Roberts, and D. S. Robson. 1985. Age-specific dose-mortality effects of Beauveria bassiana (Deuteromycotina: Hyphomycetes) on the European corn borer, Ostrinia nubilalis (Lepidoptera: Pyralidae). J. Invertebr. Pathol. 46: 259-264.

Feng, M. G., T. J. Poprawski, and G. G. Khachatourians. 1994. Production, formulation and application of the entomopathogenic fungus Beauveria bassiana for insect control: current status. Biocontr. Sci. Technol. 4: 3-34.

Goettel, M. S., T. J. Poprawski, J. D. Vandenberg, Z. Li, and D. W. Roberts. 1990. The safety to nontarget invertebrates of fungal biocontrol agents, pp. 209-231. In M. Laird, L. A. Lacey, and E. W. Davidson. [eds.], Safety of microbial insecticides. CRC, Boca Raton, FL.

Humber, R. A. 1992. Collection of entomopathogenic fungal cultures: catalog of strains. U.S. Dep. Agric. Agric. Res. Serv. ARS-110.

Ibrahim, Y. B., and W. Low. 1993. Potential of mass-production and field efficacy of isolates of the entomopathogenic fungi Beanceria bassiana and Paecilomyces fumosoroseus against Plutella xylostella. Int. J. Pest Manage. 39: $288-292$
Ignoffo, C. M., C. Garcia, M. Kroha, A. Samsinakova, and S. Kalalova. 1982. Use of larvae of Trichoplusia ni to bioassay conidia of Beauceria bassiana. J. Econ. Entomol. 75: $275-276$.

McDowell, J. M., J. E. Funderburk, D. G. Boucias, M. E. Gilreath, and R. E. Lynch. 1990. Biological activity of Beauveria bassiana against Elasmopalpus lignosellus (Lepidoptera: Pyralidae) on leaf substrates and soil. Environ. Entomol. 19: 137-141.

Pell, J. K., E.D.M. Macaulay, and N. Wilding. 1993a. A pheromone trap for dispersal of the pathogen Zoophthora radicans Brefeld. (Zygomycetes: Entomophthorales) amongst populations of the diamondback moth, Plutella xylostella L. (Lepidoptera: Yponomeutidae). Biocontrol Sci. Technol. 3: 315-320.

Pell, J. K., N. Wilding, A. L. Player, and S. J. Clark. 1993b. Selection of an isolate of Zoophthora radicans (Zygomycetes: Entomophthorales) for biocontrol of the diamondback moth Plutella xylostella (Lepidoptera: Yponomeutidae). J. Invertebr. Pathol. 61: 75-80.

Riethmacher, G. W., and J. Kranz. 1994. Development of disease incidence of Entomophthoraceae in field populations of Plutella xylostella in the Philippines. J. Plant Dis. Prot. 101: 357-367.

Shelton, A. M., R. J. Cooley, M. K. Kroening, W. T. Wilsey, and S. D. Eigenbrode. 1991. Comparative analysis of two rearing procedures for diamondback moth, Plutella $x y$ lostella (Lepidoptera: Plutellidae). J. Entomol. Sci. 26: $17-26$.

Shelton, A. M., J. L. Robertson, J. D. Tank, C. Perez, S. D. Eigenbrode, H. K. Preisler, W. T. Wilsey, and R. J. Cooley. 1993. Resistance of diamondback moth (Lepidoptera: Plutellidae) to Bacillus thuringiensis subspecies in the field. J. Econ. Entomol. 86: 697-705.

Shelton, A. M., J. D. Vandenberg, M. Ramos, and W. T. Wilsey. 1998. Efficacy and persistence of Beauteria bassiana and other fungi for control of diamondback moth (Lepidoptera: Plutellidae) on cabbage seedlings. J. Entomol. Sci. 33: 142-151.

SYSTAT. 1996. SYSTAT for Windows: statistics, version 6.0 . SPSS, Chicago, IL.

1997. SYSTAT 7.0 New Statistics. SPSS, Chicago, IL.

Talekar, N. S., and A. M. Shelton. 1993. Biology, ecology and management of the diamondback moth. Annu. Rev. Entomol. 38: 275-302.

Vandenberg, J. D. 1996. Standardized bioassay and screening of Beauveria bassiana and Paecilomyces fumosoroseus against the Russian wheat aphid (Homoptera: Aphididae). J. Econ. Entomol. 89: 1418-1423.

Vandenberg, J. D., and M. Ramos. 1997. Screening of fungal isolates against larvae of the diamondback moth, 1995. Arthropod Manage. Tests 22: 420-421.

Vandenberg, J. D., A. M. Shelton, W. T. Wilsey, and M. Ramos. 1998. Assessment of Beauteria bassiana sprays for control of diamondback moth (Lepidoptera: Plutellidae) on crucifers. J. Econ. Entomol. 91: 624-630.

Vey, A., and J. Fargues. 1977. Histological and ultrastructural studies of Beauteria bassiana infection in Leptinotarsa decemlineata larvae during ecdysis. J. Invertebr. Pathol. 30: 207-215.

Received for publication 18 July 1997; accepted 3 April 1998. 